\title{
Withdrawal right waivers for in-game currency under EU law
}

\section{Felix Hilgert*}

\begin{abstract}
Consumers in the EU have a discretionary withdrawal right for online transactions. For 14 days (or longer, if they have not been properly informed of this right), they can cancel the contract and claim a refund. This right is generally mandatory and can only be contractually waived in advance in contracts for the provision of digital content. German courts have handed down a series of judgments confirming that virtual in-game currency qualifies as digital content for the purpose of this exception and clarifying the conditions under which such waivers can be obtained. Most decisions indicate waiver language can be integrated into the purchase flow prior to the final purchase decision, with some courts requiring a separate checkbox. One decision would force providers to implement separate consent mechanisms after the consumer has made the purchase but before the virtual currency is made available to them. In any event, implementing the requirements set out by German courts also requires the cooperation of distribution platforms.
\end{abstract}

Keywords: online game, in-game currency, in-game items, digital content, withdrawal right, waiver, Consumer Rights Directive, case law

\section{Introduction}

European law has long provided for a consumer withdrawal right in distance selling and online contracts for goods and services, based in part on the rationale that consumers in those situations did not have an opportunity to inspect what they were getting prior to making their commitment. ${ }^{1}$ Although this rationale does not necessarily apply to specifically defined virtual items, ${ }^{2}$ the European legislator extended the withdrawal right to contracts for the provision of digital content other than on a physical storage medium in Article 9(2)(c) of the Consumer Rights Directive (Directive 2011/83/ EU on Consumer Rights, 'CRD').

The legislator did see the problem that the economic value of online digital content could reside in its onetime consumption, such as viewing a streamed movie, and that even where content was designed for long-term use, such as a downloadable video game, enforcing a consumer's obligation to 'return' it in the event of a withdrawal met with practical challenges. ${ }^{3}$ Unlike for other contracts, content providers were therefore given the option of asking consumers to waive the withdrawal right if they wanted access to the content before the end of the 14 day withdrawal period (Article 16(m) CRD).

Unfortunately for game publishers, the directive does not provide specific answers to the question whether small individual parts of a game, in particular virtual currency for use inside an online game, were covered by the CRD's concept of digital content, or how specifically a provider should go about obtaining a waiver with legal certainty.

Getting it wrong would have significant consequences. If virtual currency was not digital content, it is conceivable to classify it as part of a service - the operation of the game - which would mean a mandatory withdrawal right not subject to any waiver. And, if a publisher's process for obtaining a waiver was insufficient, i.e. did not comply with the requirements of the CRD (as implemented into the national law of the EU member states), then their information to customers ('You no longer have a withdrawal right') would be incorrect. This in turn would extend the initial 14 day withdrawal period to one year and 14 days under Article 10(1) CRD, and open the publisher up for additional enforcement (cf. Article 23 CRD).
Felix Hilgert, Counsel, Osborne Clarke, Germany

1 Directive $97 / 7 / \mathrm{EC}$ on the protection of consumers in respect of distance contracts, rec. 14.
2 Lutzi, Aktuelle Rechtsfragen zum Handel mit virtuellen Gegenständen in Computerspielen, NJW 2012, 2070.

3 OLG Karlsruhe, decision of 11 July 2018, docket no. 6 U 108/16 (unpublished). 
In the meantime, a series of cases from Germany has shed some light on these open questions. Since Article 4 CRD provides for full harmonisation, this guidance could be useful throughout the EU in the absence of a body of CJEU case law.

\section{In-game currency as digital content}

Digital content is defined in Article 2(11) of the CRD as data which are produced and supplied in digital form. Recital 19 goes into slightly more detail and clarifies that digital content includes, without limitation, computer programs, applications, games, music, videos or texts, irrespective of whether they are accessed through downloading or streaming, from a tangible medium or through any other means.

The definition of the directive has been implemented in German law in section 312f(3) of the German Civil Code (Bürgerliches Gesetzbuch, 'BGB'), and the contents of recital 19 of the CRD are reflected in the legislator's explanatory notes on the act implementing the CRD. $^{4}$

In 2016, a German consumer group took issue with the withdrawal right language and general design of the purchase flow for virtual currency for an online game. They deemed the information language for consumers insufficient (an issue which we shall discuss in section 3 below), but also argued that regardless of how clearly and conspicuously a games provider might explain the withdrawal right waiver, this could not apply to virtual currency, since it could not be qualified as virtual content.

The consumer group essentially advanced three arguments to support this position: They claimed that virtual currency was not content at all because it lacked any information other than as a device to count payment (and should therefore be treated like a payment instrument). They argued that virtual currency was not downloaded to the player's device. Finally, they said the provisions allowing for a withdrawal right waiver for digital content should not apply where the purpose of this exception was irrelevant, i.e. where a provider could easily remove the virtual currency from the player's account. ${ }^{5}$

The second and the third argument are relatively easy to counter. The CRD and its German implementation expressly do not limit the concept of digital content to such content that is downloaded. Both recital 19 of the CRD and the German legislator's explanatory note expressly mention streaming as one way to deliver digital content. ${ }^{6}$ And the consumer group's final argument does not take into account the possibility that players may use the virtual currency to trigger some action within the game right after purchase that cannot be undone (such as unlocking and playing additional content). ${ }^{7}$ To take the argument to its logical extreme, whether or not something was digital content or not, and whether or not a waiver was possible, would then depend on what the consumer did with it after purchase. This cannot have been the intention of the EU legislator, because it would make it impossible for a provider to comply with their obligation under Article 6(1)(h) CRD to inform consumers about their withdrawal right (if any) in a clear and comprehensible manner prior to any online transaction.

The first argument does merit a closer look. Whereas Article 2(11) CRD only speaks of 'data', which can clearly apply to even the smallest units of information, the examples of types of digital content provided in recital 19 of the CRD all describe concepts that imply a sense of a 'complete' product, such as a game, app, song or movie, and not just a part or an excerpt. However, this does not seem like a good reason to exclude parts or excerpts from the definition of such content which begs the question where the line would have to be drawn. In the realm of online games, would it really be justifiable to treat an add-on differently from a standalone sequel, and what would be the legal status of the former, if not digital content? The interests of the customer and the provider that the special rules for digital content intend to balance are the same in both cases. Therefore, the definition of digital content must apply to any data that is part of a game.

The Regional Court of Karlsruhe agreed with this analysis. It found that because the virtual currency could not be transferred out of the player's account (to other players or other games) and extended the player's scope of gameplay options, it had to be considered an integral part of the game and was therefore digital content for the purposes of the CRD and section $312 \mathrm{f}(3)$ BGB. $^{8}$

8 LG Karlsruhe BeckRS 2016, 12084; ECLI:DE:LGKARLS:2016:0525.18O7.16.0A.; expressly confirmed on appeal by OLG Karlsruhe, decision of 11 July 2018, docket no. 6 U 108/16 (unpublished). This analysis implies that virtual currency in a 'digital wallet' on a games platform may not be deemed digital content if it can be redeemed for different games or content within different games, but the court of course did not have to address this issue. 


\section{Formal waiver requirements}

This left the question of how exactly publishers can build a formally valid withdrawal rights waiver into their purchase flows.

\subsection{General requirements}

Article $16(\mathrm{~m}) \mathrm{CRD}$ and the almost verbatim implementation in section 365(5) BGB provide that the withdrawal right does not apply if the performance has begun with the consumer's prior express consent and his acknowledgment that he thereby loses his right of withdrawal. Recital 19 of the CRD is slightly more specific and provides that the consumer should have a right of withdrawal unless he has consented to the beginning of the performance of the contract during the withdrawal period and has acknowledged that he will consequently lose the right to withdraw from the contract.

Technically, the consumer therefore does not waive the withdrawal right - they (merely) consent to the provider beginning with the performance (i.e. making content available) before the withdrawal period has elapsed. However, they have to acknowledge that this consent amounts to a loss of the withdrawal right once the provider actually does begin the performance.

This final aspect can be an important nuance, because even if the consumer consents, they still keep their withdrawal right until performance actually begins. However, the threshold of 'beginning' performance is low. In a case involving the subscription to a streaming service, the Higher Regional Court of Munich held that performance began, and the withdrawal right therefore entirely lapsed, as soon as the provider emailed the subscriber their personal login credentials - even if they had not logged in or watched any of the content yet. ${ }^{9}$

\subsection{The Karlsruhe cases}

In the case before the Regional Court of Karlsruhe, the games company had included language next to the purchase button that closely mirrored the wording of the CRD. It said: 'By clicking "Buy Now" I consent to immediate performance by [Provider] and acknowledge that my withdrawal right thereby lapses.'

Surprisingly, though, the court found this to be insufficient. Taking a very formalistic approach, the court said

9 OLG München BeckRS 2016, 16429; ECLI:DE:OLGMUEN:2016: 0630.6U732.16.0A.

10 LG Karlsruhe BeckRS 2016, 12084; ECLI:DE:LGKARLS:2016:0525. 18O7.16.0A.

11 OLG Karlsruhe, decision of 11 July 2018 , docket no. 6 U 108/16 (unpublished). that in order for a withdrawal right to lapse, it must first have arisen, which does not happen until the relevant contract has been formed. Therefore, a consumer could not waive the right before or at the same time as forming the contract (by clicking the 'Buy Now' button). ${ }^{10}$

On appeal, the Higher Regional Court of Karlsruhe disagreed, but still found against the games provider. The court acknowledged that the withdrawal right waiver mechanism also serves the purpose of protecting providers against abuses of the withdrawal right in the digital space. It stated that it would amount to excessive formality to require a separate declaration of consent after purchase, and that consumers could be asked to make their declarations regarding the formation of the contract and consent to immediate performance (resulting in the withdrawal right waiver) with one click. However, the judges found the wording, font size and placement of the waiver language (smaller than the purchase price and to the left of the purchase button) insufficient to make it clear to the consumer that they would not be able to withdraw, adding that the purchase button itself only said 'Buy Now' and did not mention the waiver. $^{11}$

\subsection{The Berlin case}

In a case involving the withdrawal rights waiver of an online dating website, the Regional Court of Berlin adopted the requirement of separate consent, but also found that this consent could be declared at the same time as the purchase as long as the consumer had activated an according checkbox in the purchase flow. ${ }^{12}$

The court referred to section 12.2 of the EU Commission's guidance on the interpretation of the CRD, ${ }^{13}$ which states that the requirement of express consent in the context of Article 16(m) CRD should be interpreted in the same way as the requirement for express consent in Article 22 CRD. The latter states that any extra payments (in addition to the agreed payment for the main contractual obligations) cannot be agreed by a default setting that the consumer must actively reject.

According to the court, if the withdrawal right waiver language is purportedly accepted by clicking the purchase button, this has the same effect as a default, and is not sufficient in order to alert the consumer to the consequences of their actions.

12 LG Berlin, BeckRS 2016, 13955; ECLI:DE:LGBE:2016:0630.52O340.15.0A.

13 DG Justice Guidance Document concerning Directive 2011/83/EU, available at https://ec.europa.eu/info/sites/info/files/crd_guidance_en_0_updated_0. pdf. 


\subsection{The Cologne case}

Most recently, the Regional Court of Cologne reiterated the position of the Regional Court of Berlin (ignoring the case law of the Higher Regional Court of Karlsruhe) in a case pitting a consumer group against an online video download platform that also purported to obtain withdrawal right waivers by a click on the purchase button. Again, the court refers to the EU Commission guidance document and states that unless the consumer activates a separate checkbox, it is not sufficiently certain that they have noticed and contemplated the withdrawal right waiver prior to making their purchase. ${ }^{14}$

\subsection{Critical analysis}

At first glance, the position of the Regional Court of Karlsruhe is supported by a very literal interpretation of recital 19 of the CRD, which - both in the English and the German language versions of the directive - refers to a declaration of consent of the consumer 'during' the withdrawal period - implying that this must happen after that period has started. However, other language versions of the recital, in particular the Danish version, use wording that cannot be understood in this sense. ${ }^{15}$ Since Article 3 of Regulation (EEC) 1/1958 requires all language versions of an EU directive to be equally legally binding, ${ }^{16}$ courts should not attach too much weight to such literal interpretations that are not uniform across all language versions.

The decision of the Higher Regional Court of Karlsruhe is helpful in this regard, but unfortunately ultimately sidesteps the issue. By basing its decision on specificities of the purchase flow, it demotes its convincing arguments to obiter dicta. Finally, when it criticizes the game provider's labelling of the purchase button only with 'Buy Now!', it fails to take into account the mandatory requirements of Article 8(2) CRD. ${ }^{17}$

The Regional Courts of Berlin and Cologne also insist on a separate waiver procedure, but their reasoning is unconvincing. To begin with, the EU Commission's guidance document should not be taken as binding law, but as one of several possible interpretations. ${ }^{18}$ Articles $16(\mathrm{~m})$ and $22 \mathrm{CRD}$ are not necessarily quite as parallel as that

14 LG Köln, decision of 21 May 2019, docket no. 31 O 372/17 (unpublished and still subject to appeal at the time of writing).

15 The relevant sentence in the Danish version reads 'I forbindelse med sådanne aftaler bør forbrugeren have en fortrydelsesret, medmindre forbrugeren har givet sit samtykke til, at leveringen i medfør af aftalen påbegyndes inden fortrydelsesfristen udløber, og har anerkendt, at vedkommende dermed vil miste sin fortrydelsesret.', which must be translated as 'In the case of such agreements, the consumer should have a right of withdrawal, unless the consumer has consented that the delivery under the agreement commence before the expiry of the withdrawal period and has acknowledged that he will thereby lose his right of withdrawal.' (emphasis added). guidance suggests: In fact, Article 22 concerns optional services, i.e. additional options that a consumer may order or not order. If the consumer does not order them, nothing changes for the trader's primary obligation and business model. Article $16(\mathrm{~m})$ on the other hand concerns a decision that is crucial for the trader's performance of their primary obligation.

It is also not clear why these courts believe that only a separate checkbox could ever be sufficient to alert a customer to the fact that they may not have a withdrawal right. While Article 8(2) CRD will prevent this information from going directly on the purchase button, there is no reason why a clearly worded notice in a large, conspicuous font immediately adjacent to the purchase button and visible without scrolling should not achieve this purpose.

Finally, while the Regional Court of Berlin rendered its judgment before the Higher Regional Court of Karlsruhe, the Regional Court of Cologne could and should have followed that court's guidance.

\section{Outlook}

One thing is clear in German case law: it cannot be sufficient to bury withdrawal rights waivers in the terms and conditions of a distribution platform or online storefront. Even the Higher Regional Court of Karlsruhe with its more practical approach requires a very conspicuous notice.

At the time of writing, the decision of the Regional Court of Cologne was still subject to appeal, and with only a few available decisions, it would be premature to speak of settled case law, in particular because German law does not have a formal stare decisis principle.

However, it would be a prudent approach for publishers wishing to obtain withdrawal right waivers to implement and document a separate consent mechanism.

Where games are distributed through third party platforms such as the Apple App Store, this requires the cooperation of such third parties. We have already seen Apple occasionally using separate dialogue boxes after confirmation of higher-value in-app purchases to request consent for immediate performance and acknowledge the loss of the withdrawal right.
16 cf. CJEU Case C-361/01 - Kik; ECLI:EU:C:2003:434 at para 87.

17 This provision requires that the purchase button be labelled 'only with the words "order with obligation to pay" or a corresponding unambiguous formulation' (emphasis added); German courts have been very strict against e-commerce traders that added other information to the button itself, cf. OLG Köln BeckRS 2016, 4482; ECLI:DE:OLGK:2016: 0203.6U39.15.00.

18 The Higher Regional Court of Karlsruhe mentioned both the Berlin decision and the EU Commission Guidance in its judgment and still concluded that a separate checkbox was dispensable. 